\title{
Corrigendum to "Quality and Pricing Decisions in a Two-Echelon Supply Chain with Nash Bargaining Fairness Concerns"
}

\author{
Ji-cai Li $\mathbb{D},{ }^{1}$ Jing-hong Lu, ${ }^{1}$ Qi-liang Wang, ${ }^{2}$ and Changwen Li $\mathbb{D}^{3}$ \\ ${ }^{1}$ College of Xingzhi, Zhejiang Normal University, Jinhua 321004, China \\ ${ }^{2}$ School of Economics and Management, Zhejiang Normal University, Jinhua 321004, China \\ ${ }^{3}$ School of Economics, Huaibei Normal University, Huaibei 235000, China \\ Correspondence should be addressed to Ji-cai Li; leejicai@163.com
}

Received 26 June 2018; Accepted 16 July 2018; Published 1 August 2018

Copyright (c) 2018 Ji-cai Li et al. This is an open access article distributed under the Creative Commons Attribution License, which permits unrestricted use, distribution, and reproduction in any medium, provided the original work is properly cited.

\begin{abstract}
In the article titled "Quality and Pricing Decisions in a Two-Echelon Supply Chain with Nash Bargaining Fairness Concerns" [1], the name of the second author was given incorrectly as Ji-hong Lu. The author's name should have been written as Jing-hong Lu. The revised authors' list is shown above.
\end{abstract}

\section{References}

[1] J.-C. Li, J.-H. Lu, Q.-l. Wang, and C. Li, "Quality and pricing decisions in a two-echelon supply chain with nash bargaining fairness concerns," Discrete Dynamics in Nature and Society, vol. 2018, Article ID 4267305, 19 pages, 2018. 


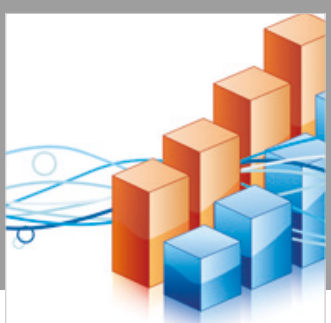

Advances in

Operations Research

\section{-n-m}
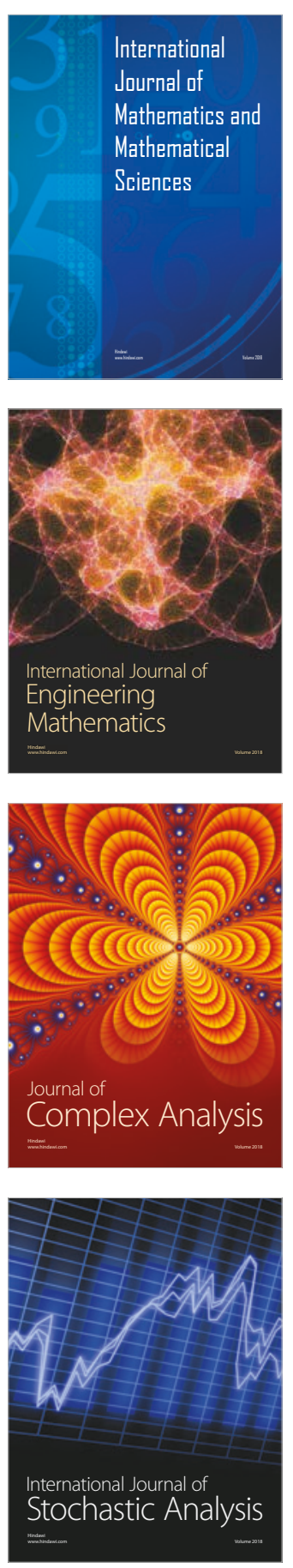
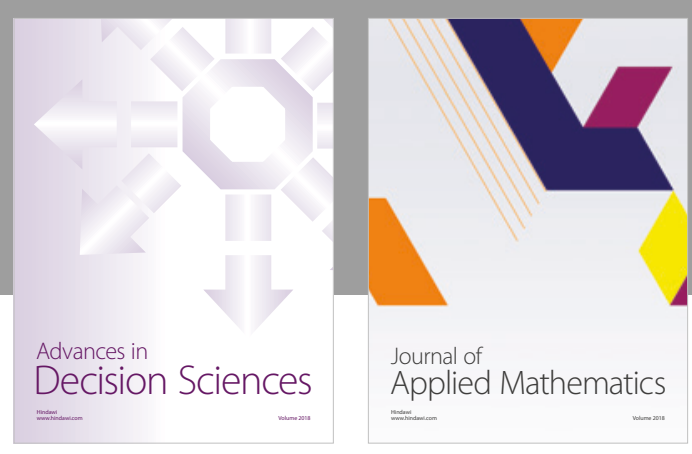

Journal of

Applied Mathematics
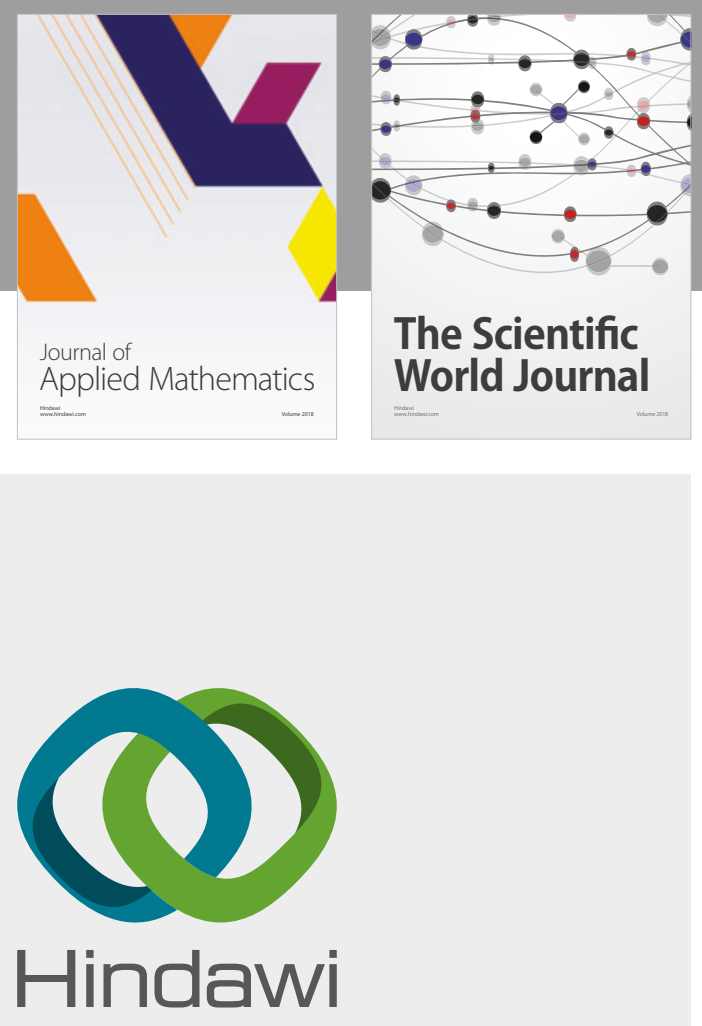

Submit your manuscripts at

www.hindawi.com

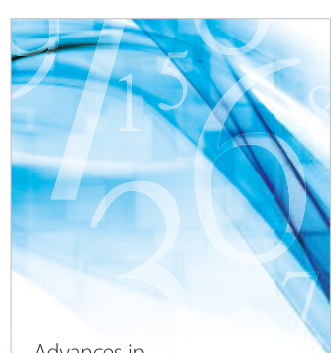

Advances in
Numerical Analysis
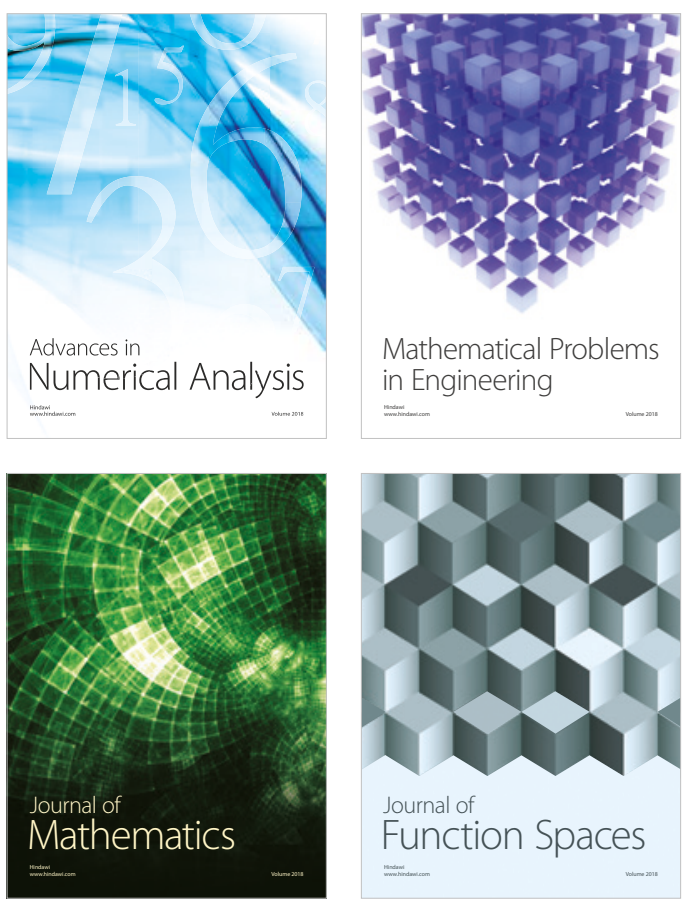

Mathematical Problems in Engineering

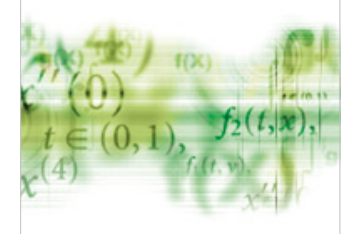

International Journal of

Differential Equations

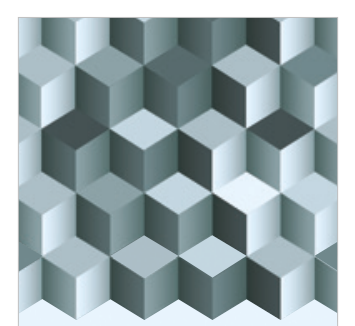

Journal of

Function Spaces

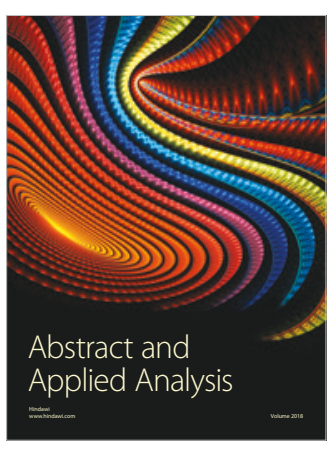

The Scientific

World Journal

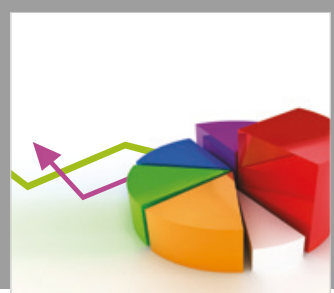

Journal of

Probability and Statistics
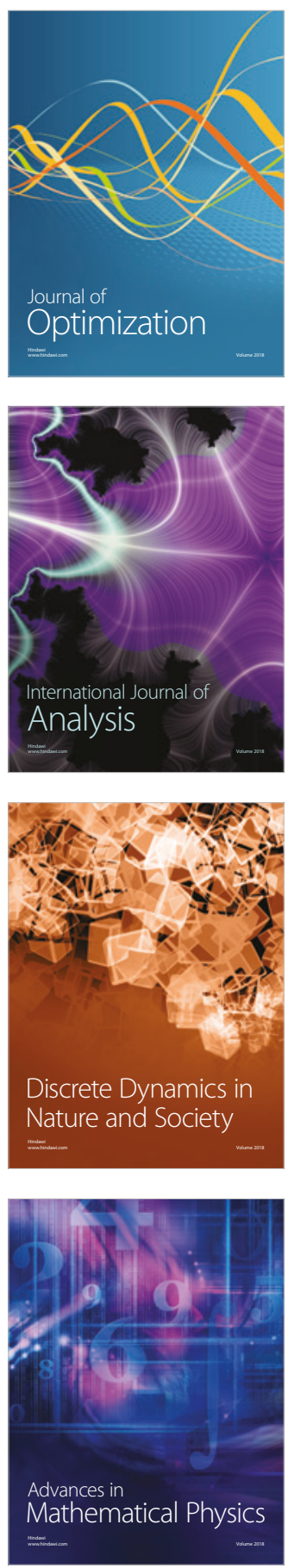